\title{
ERRATUM
}

\section{Initially fewer bloodstream infections for allogeneic versus autologous stem-cell transplants in neutropenic patients - ERRATUM}

\section{S. HIEKE, H. BERTZ, M. DETTENKOFER, M. SCHUMACHER} AND J. BEYERSMANN

doi: 10.1017/S0950268812000283, Published by Cambridge University Press, 7 March 2012.

In the article by S. Hieke, H. Bertz, M. Dettenkofer, M. Schumacher, and J. Beyersmann [1] there was an error in the annotation of the $\mathrm{Y}$-axis in figure 2 (b).

Figures 2 (a) and (b) are reproduced below with the correct annotation.
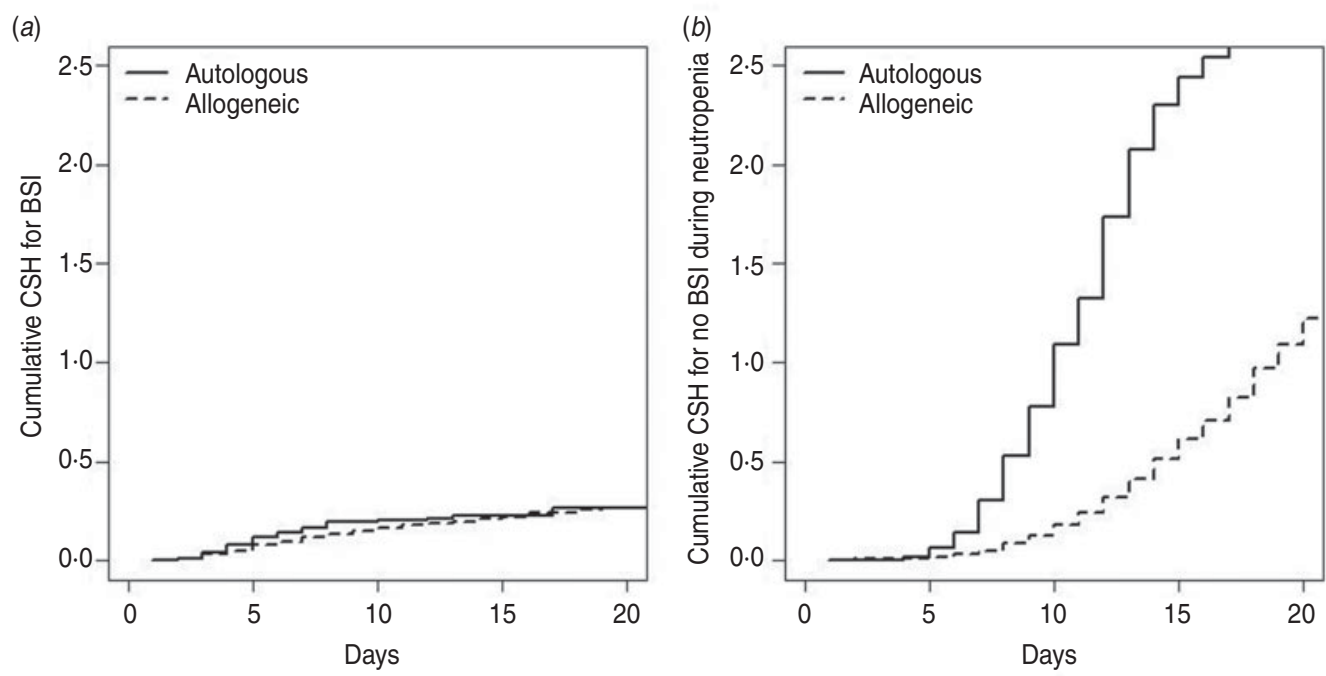

Fig. 2. Nelson-Aalen estimates of the cumulative cause-specific hazards (CSH) within the transplant group. BSI, Bloodstream infection.

\section{REFERENCE}

1. Hieke S, Bertz H, Dettenkofer M, Schumacher M, Beyersmann J. Initially fewer bloodstream infections for allogeneic vs. autologous stem-cell transplants in neutopenic patients. Epidemiology and Infection, 2013; 141: $158-164$. 